\title{
NOVOS AVANÇOS RELACIONADOS AO HIV/AIDS
}

\author{
Aline Tamisa Oliveira Santos Enfermeira. Graduada pela \\ Universidade do Estado da Bahia \\ Terezinha Andrade Almeida Enfermeira. Mestre em Enfermagem \\ pela Universidade Federal da Bahia. \\ Professora Adjunta do Curso de \\ Enfermagem da Universidade do \\ Estado da Bahia
}

\author{
Tânia Christiane Ferreira Bispo Enfermeira. Doutora pelo Instituto de \\ Saúde Coletiva da Universidade \\ Federal da Bahia. Professora Adjunta \\ do Curso de Enfermagem da \\ Universidade do Estado da Bahia
}

\author{
Augusto Cesar Costa Cardoso Professor Adjunto da Escola Bahiana \\ de Medicina e Saúde Publica. PhD em \\ Saúde Coletiva.
}

\begin{abstract}
Resumo
Apesar de muito falar-se sobre HIV/AIDS como problema de saúde pública mundial, a doença mantém uma elevada magnitude em diversos países. Deve-se alertar para o caráter heterogêneo da epidemia, no decorrer das últimas décadas, em diferentes localidades e grupos humanos. Porém, apesar da relevância do HIV/AIDS e de seus multifatores para a área da saúde e da sociedade em geral, o aprofundamento deste tema tem sido pouco explorado nas Universidades. Este estudo teve como objetivo identificar os novos avanços sobre o HIV/AIDS, considerando a importância da atualização das informações sobre tema de tanta relevância. O aperfeiçoamento dos estudos sobre o tema contribui para o fortalecimento das atualizações necessárias devido ao seu caráter especializado, visando uma reflexão sobre o assunto de maneira a torná-lo cada vez mais apropriado. Foi identificado que parte das informações sobre a temática não faziam parte do conhecimento geral dos profissionais da área de saúde, apesar dos avanços referentes aos multifatores do HIV e se agrava quando da análise junto aos estudantes do campo da saúde.
\end{abstract}

Descritores: HIV; AIDS; Novos avanços.

\section{NEW ADVANCES RELATED TO HIV/AIDS}

\begin{abstract}
Despite much talk about HIV/AIDS as a public health problem worldwide, the disease has a high magnitude in several countries. It's important to call attention to the heterogeneous character of the epidemic, over the last decades, in different locations and human groups. However, despite the relevance of HIV/AIDS and its multifactors for the health area and society in general, the deepening of this theme has been little explored in the Universities. This study aimed to identify new advances on HIV/AIDS, considering the importance of updating the information on a theme of much relevance. The improvement of studies on the subject contributes to the strengthening of required updates due to their specialized nature, aiming to reflect on the matter so as to make it increasingly appropriate. It was reported that part of the information on the subject were not part of the general knowledge of health professionals, despite advances related to multifactors of HIV and it worsens when the analysis is with students in the health field.
\end{abstract}

Keywords: HIV; AIDS; New Advances

Revista Enfermagem Contemporânea, Salvador, dez. 2012; 1(1): 80-102.

http://www.bahiana.edu.br/revistas 


\title{
NUEVOS AVANCES RELACIONADOS AL HIV/SIDA.
}

\begin{abstract}
Resumen
A pesar de que se habla mucho sobre HIV/SIDA como problema de salud pública mundial, la enfermedad se mantiene en una elevada magnitud en diversos países. Se debe alertar para el carácter heterogéneo de la epidemia, en el transcurso de las últimas décadas, en diferentes localidades y grupos humanos. No obstante, a pesar de la relevancia del HIV/SIDA y de sus múltiples factores para el área da salud y de la sociedad en general, la profundización de este tema ha sido poco explorado en las Universidades. Este estudio tiene como objetivo identificar los nuevos avances sobre el HIV/SIDA, considerando la importancia de la actualización de las informaciones sobre un tema de tanta relevancia. El perfeccionamiento de los estudios sobre el tema contribuye para el fortalecimiento de las actualizaciones necesarias debido a su carácter especializado, generando una reflexión sobre el tema de manera a hacerlo cada vez mas apropiado. Fue identificado que parte de las informaciones sobre la temática no forman parte del conocimiento general de los profesionales del área de salud, a pesar de los avances referentes a los múltiples factores del HIV y se agrava cuando el análisis es realizado con estudiantes del área de salud.
\end{abstract}

Palabras clave: HIV; SIDA; Nuevos Avances.

\section{INTRODUÇÃO}

O Vírus da Imunodeficiência Humana, conhecido como HIV (Human Immunodeficiency Virus), é um vírus pertencente à classe dos retrovírus e causador da AIDS (Síndrome da Imunodeficiência Humana), sigla em inglês da síndrome da imunodeficiência adquirida. Ao entrar no organismo humano, o HIV age no interior das células do sistema imunológico, responsável pela defesa do corpo. As células de defesa mais atingidas pelo vírus são os linfócitos CD4+, justamente aquelas que comandam a reposta específica de defesa do corpo diante de agentes como vírus e bactérias. As células do sistema imunológico de uma pessoa infectada pelo vírus começam então a funcionar com menos eficiência e, com o tempo, a capacidade do organismo em combater doenças comuns diminui, deixando a pessoa sujeita ao aparecimento de vários tipos de doenças e infecções. ${ }^{(1)}$

O HIV pode levar vários anos, entre o momento da infecção até o surgimento dos primeiros sintomas da AIDS. Esta fase se denomina de assintomática, pois a pessoa não apresenta nenhum sintoma ou sinal da doença. Este período entre a infecção pelo HIV e a manifestação dos primeiros sintomas da AIDS irá depender, principalmente, do estado de saúde da pessoa. Quando se diz que uma pessoa tem HIV, está fazendo referência a essa fase assintomática da doença. Quando se fala em pessoa com AIDS, significa dizer que ela já apresenta sintomas que caracterizam a doença, o que geralmente marca o início do tratamento com os medicamentos antiretrovirais, que combatem a reprodução do vírus HIV. ${ }^{(2)}$

Estima-se que nos dias atuais 600 mil pessoas no Brasil vivam com o HIV ou já tenham desenvolvido a AIDS. O HIV entra no organismo humano e pode ficar incubado por 
muitos anos sem que o indivíduo apresente nenhum sintoma ou sinal de doença. Esse período gira em torno de oito anos. A AIDS é o estágio mais avançado da infecção pelo HIV, sendo que uma pessoa pode passar muitos anos com o vírus sem apresentar sintoma algum. ${ }^{(3)}$

Do ano de 1980 a junho de 2007 foram notificados 474.273 casos de AIDS. A incidência de AIDS tende à estabilização. No Norte e Nordeste, a tendência é de crescimento. Segundo critérios da Organização Mundial de Saúde (OMS), o Brasil tem uma epidemia, com taxa de prevalência da infecção pelo HIV é de $0,6 \%$ na população de 15 a 49 anos. ${ }^{(4)}$

A temática do Vírus da Imunodeficiência Humana (HIV) e da Síndrome da Imunodeficiência Adquirida (AIDS) consiste em um dos grandes problemas contemporâneos da Saúde Pública, trazendo implicações para a sociedade em suas diversas dimensões, perpassando por aspectos objetivos e subjetivos. O HIV apesar de possuir maior magnitude, caracteriza-se pela sua considerável invisibilidade, já a AIDS é descrita pela sua magnitude estimada em termos de impacto social. ${ }^{(5)}$

Estima-se que cerca de 630 mil pessoas vivam com HIV ou AIDS no Brasil. Segundo parâmetros da Organização Mundial de Saúde (OMS, 2007). Por seu caráter pandêmico e sua gravidade, a AIDS representa um dos maiores problemas de saúde pública da atualidade. No Brasil, desde a identificação do primeiro caso em 1980 até junho de 2008, já foram identificados, aproximadamente, 506 mil casos da doença. Sendo que pelo Sistema de Informação de Agravos de Notificação (SINAN) foram identificados 11.523 óbitos em 2008, sendo 6,1 por 100.000 habitantes. ${ }^{(6)}$

No Brasil, as ações desenvolvidas para a prevenção das ISTs, tratando-se especificamente do HIV/AIDS, a promoção da saúde prima pela recomendação do uso do preservativo em todas as relações sexuais. Abordagens que recomendam a diminuição do número de parceiros, a abstinência e a fidelidade não têm tido impacto entre as pessoas sexualmente ativas. A inserção do aconselhamento e do diagnóstico do HIV na rotina dos serviços da rede básica de saúde implica em uma reorganização do processo de trabalho da equipe e do serviço como um todo. Requer uma atenção para o tempo de atendimento, reformulações de fluxo da demanda, funções e oferta de atividades nos serviços. ${ }^{(7)}$

Estimular mudanças de valores e práticas exige uma preparação da equipe/serviço para acolher a subjetividade dos portadores, sendo parte essencial dessa conhecer as principais vulnerabilidades para a infecção do HIV, as necessidades particulares dos usuários de saúde, 
suas características e estilos de vida e desenvolver uma abordagem sobre os riscos, respeitando as suas especificidades, minimizando assim risco de novas infecções pelo vírus.

O diagnóstico precoce também possibilita uma assistência adequada ao portador do vírus, controlando o desenvolvimento da AIDS. A institucionalização dessas ações permite a redução do impacto da epidemia na população, a promoção de saúde e a melhoria da qualidade do serviço prestado nas unidades de saúde. Permite também conhecer e aprofundar o perfil social e epidemiológico da comunidade de abrangência, dimensionar e mapear a população de maior vulnerabilidade e, com isso, reformular estratégias de prevenção e monitoramento. Há populações que são fortemente estigmatizadas e historicamente excluídas dos serviços, como, por exemplo, travestis, profissionais do sexo masculino e feminino, usuários de drogas, homossexuais, jovens em situação de rua. É importante a promoção e a ampliação do acesso dessas pessoas ao serviço, aos insumos de prevenção, ao diagnóstico com aconselhamento. ${ }^{(7)}$

A Lei Federal 9.313, de 13 de novembro de 1996, é uma conquista da sociedade brasileira organizada, pois garantiu o acesso universal e gratuito ao tratamento antirretroviral no Brasil. Ao longo do tempo, foi também estruturado, o acesso da população aos exames de monitoramento laboratorial da infecção pelo HIV, bem como aos insumos e ações de prevenção. $^{\left({ }^{8}\right)}$

Tais conquistas são construídas, no Brasil, em sintonia com princípios e diretrizes que regem o Sistema Único de Saúde: equidade, integralidade e participação social. Essas dimensões se desdobram em distintos campos de ação na experiência brasileira de luta contra a epidemia, construindo inclusão, combate ao estigma e respeito a todos. Envolve, também, um conjunto de ações que vão desde os aspectos relacionados a prevenção, acolhimento, aconselhamento, auto cuidado e monitoramento nas diferentes fases de evolução da doença, até os aspectos clínicos, psicossociais, econômicos e epidemiológicos, direcionando essas ações para a valorização da vida e propiciando qualidade no viver das pessoas vivendo com HIV/AIDS. ${ }^{(8)}$

A resposta nacional à prevenção do HIV é o trabalho que vem sendo executado tanto pelo governo quanto pela sociedade civil há quase duas décadas, com o objetivo de superar o maior número possível de obstáculos impostos pela doença, desde o início da epidemia até os dias de hoje. Acompanhando todas as fases do HIV/AIDS, encontra-se a profissão da 
Enfermagem, visto o cuidado e o bem-estar dos indivíduos a sua base de atuação, além de tratamento desta patologia, diagnóstico e busca da qualidade de vida.

\section{OBJETIVO}

Identificar novas tecnologias e informações sobre os multifatores da HIV/AIDS para o melhor enfrentamento dos profissionais de saúde, assim como melhor compreensão sobre a elaboração e implementação de políticas públicas no que se refere a este importante problema de saúde pública.

\section{METODOLOGIA}

Com o intuito de atingir os objetivos propostos foi realizada uma pesquisa bibliográfica integrativa ${ }^{(9)}$ a qual segui etapas como escolha do tema, levantamento bibliográfico preliminar, formulação do problema, busca de fontes, leitura e organização dos materiais e redação do texto. ${ }^{(21)}$

A presente pesquisa é do tipo exploratório descritiva e os trabalhos resultantes ou não de pesquisas foram definidos como produção científica. Para obtenção dos dados, utilizou-se o levantamento bibliográfico realizado nas bases de dados Medline, Lilacs, SciELO, Banco de Dados do Ministério da Saúde, Universidade do Estado da Bahia, além de anais de congressos e simpósios onde o tema foi referido.

Foram identificadas as produções científicas e manuais a respeito do HIV/AIDS e seus multifatores. De todas as referências listadas, foram selecionadas somente as publicadas em periódicos de língua portuguesa, inglesa e/ou espanhola.

A busca das referências foi realizada no Sistema de Bibliotecas da UNEB e na Biblioteca. Para a categorização das áreas temáticas, foi analisado além dos títulos, o conteúdo, uma vez que o título nem sempre é indicativo da abrangência do assunto. ${ }^{(21)}$ Quanto à especialidade dos periódicos, foram consultados o International Nursing Index e o Index Medicus para a classificação dos mesmos. Em relação à categoria profissional e área de atuação dos autores, foram consideradas as informações constantes abaixo do título, em notas de rodapé ou no final de cada publicação, onde são citados os dados do autor. 
A motivação pela escolha deste tema deu-se devido ao contato com os multifatores decorrentes do HIV/AIDS em estágios curriculares, sendo necessários estudos de aprofundamento para suporte de atuação prática.

Realizada a delimitação do tema, o levantamento bibliográfico foi de fundamental importância para a formulação do problema de pesquisa e enfoque abordado. A leitura seletiva foi uma etapa para a seleção do conteúdo mais importante.

\section{RESULTADOS E DISCUSSÃO}

\section{HISTÓRICO DO HIV/AIDS}

Ao longo da história milenar das Infecções Sexualmente Transmissíveis (IST), o estigma e o preconceito sempre se fizeram presentes, a ponto de se constituírem numa interferência negativa nas questões do seu enfrentamento. A identificação do Vírus da Imunodeficiência Humana (HIV) e da síndrome da imunodeficiência adquirida (AIDS) ocorreu há pouco mais de duas décadas, porém, o número de pessoas infectadas e doentes tem aumentado vertiginosamente nesse curto período de tempo.

O vírus da imunodeficiência humana é da família dos retrovírus. Esta designação contém pelo menos duas sub-categorias de vírus, o HIV-1 e o HIV-2. No grupo HIV-1. Esses dois grupos tem diferenças consideráveis, sendo o HIV-2 mais comum na África Subsaariana e bem incomum em todo o resto do mundo. ${ }^{(20)}$ Portugal é o país da Europa com maior número de casos de HIV-2, provavelmente pelas relações que mantém com diversos países africanos. É estimado que $45 \%$ dos portadores de HIV em Lisboa tenham o vírus HIV-2. ${ }^{(20)}$ Em 2008, a OMS estimou que existam 33,4 milhões de infectados, sendo 15,7 milhões mulheres e 2,1 milhões jovens abaixo de 15 anos. O número de novos infectados no ano de 2009 foi de 2,6 milhões. O número de mortes de pessoas com AIDS é estimado em 1,8 milhões. ${ }^{(6)}$

De acordo com o Programa Nacional de AIDS, a infecção pelo HIV começou a ser observada na metade do século XX. Os relatos iniciais contam que a doença surgiu na África Central e, provavelmente, pela mutação dos vírus do macaco. Algumas experiências comprovam que o elo perdido na passagem dos primatas para o homem parece estar relacionado com a questão da manipulação de carnes de chimpanzés infectados na África. A 
doença, então levada para pequenas comunidades da região central, disseminou-se pelo mundo todo com a globalização. ${ }^{(5)}$

Segundo dados da Organização Mundial de Saúde (OMS), estima-se que cerca de 5 milhões de pessoas irão adquirir o HIV em 2003, resultando numa estimativa global de 40 milhões de pessoas vivendo com o vírus. No Brasil, até dezembro de 2002 foram notificados 257.780 casos de AIDS, estimando-se que existem aproximadamente de 600 mil portadores do HIV. O último boletim da UNAIDS projeta cerca de 33,2 milhões de pessoas que vivem com o HIV em todo o mundo no final de 2007, a maioria na África. Segundo a UNAIDS (2008), dois terços dos infectados estão na África sub-saariana. ${ }^{(10)}$

A síndrome da imunodeficiência adquirida foi reconhecida em meados de 1981, nos EUA, a partir da identificação de um número elevado de pacientes adultos do sexo masculino, homossexuais e moradores de São Francisco, que apresentaram "sarcoma de Kaposi", pneumonia por Pneumocystis carinii e comprometimento do sistema imune, os quais, hoje são características típicas da doença. Já no Brasil, os primeiros casos confirmados foram 1982, no estado de São Paulo, e, desde o início da década de 1980 até hoje, existem aproximadamente 600 mil brasileiros com o vírus da AIDS. Do total de casos da doença, mais de 80\% concentram- se nas regiões Sudeste e Sul. O Sudeste é a região mais atingida desde o início da epidemia e, apesar da alta taxa de incidência, mostra moderada estabilização desde 1998. Na região Sul, observa-se aumento das taxas de incidência de casos até 2003, apresentando queda da taxa em 2004. ${ }^{(5)}$

Há relativa tendência de expansão do número de casos entre as populações com baixo nível de renda e escolaridade, atingindo camadas sociais sem nenhuma ou quase nenhuma proteção social, tendência que é denominada por alguns autores como a "pauperização" da epidemia brasileira. Apesar de os casos se concentrarem nas áreas urbanas e regiões metropolitanas, verifica-se um processo de interiorização da infecção no País, para municípios de médio e pequeno porte, e consubstanciando a assim chamada feminização da epidemia, cresce significativamente o número de mulheres infectadas pelo HIV. ${ }^{(11)}$

\section{EXPECTATIVA DE VIDA PARA O SOROPOSITIVO}

O termo qualidade de vida é bastante abrangente, estando diretamente relacionado às experiências individuais, num dado momento dentro de um contexto sociocultural. A 
qualidade de vida relacionada à saúde é considerada um conceito muito mais amplo, uma vez que tanto os conceitos de qualidade de vida global quanto aqueles relacionados ao próprio estado de saúde.

Desde o início da epidemia, o Programa Nacional DST/AIDS do Ministério da Saúde em conjunto com as Secretarias Estaduais e Municipais de Saúde tem se empenhado na elaboração e implementação de políticas públicas éticas, efetivas e democráticas no que se refere ao HIV/AIDS.

A assistência de excelência ao paciente com essa doença requer aplicação cotidiana de princípios de cuidado primário, medicina de família e abordagem de doenças crônicas. $\mathrm{O}$ conhecimento básico sobre múltiplas especialidades para o manejo adequado das complicações freqüentemente associadas à infecção pelo HIV é fundamental, bem como, a atualização contínua sobre a terapia anti-retroviral. Recomenda-se, portanto, que o tratamento seja, sempre que possível, conduzido por médico experiente no manejo de pacientes infectados pelo HIV, preferencialmente integrado em equipe multidisciplinar. ${ }^{(12)}$

A Política de Acesso Universal ao Tratamento tem garantido, no âmbito do Sistema Único de Saúde, acesso e gratuidade, bem como importante redução na mortalidade e na ocorrência de manifestações oportunistas em pessoas vivendo com HIV e AIDS (PVHA). Sua normatização foi definida pela Lei n. ${ }^{\circ}$ 9.313/96, sendo responsabilidade do Governo Federal a disponibilização do tratamento anti-retroviral às pessoas que vivem com HIV e AIDS, dentro de parâmetros técnicos e científicos estabelecidos pelo Ministério da Saúde, por intermédio do Programa Nacional de DST e AIDS. Dentro desta regulamentação, foi instituído o Comitê Assessor para Terapia Anti-retroviral em Adultos e Adolescentes para tratar de forma técnica os aspectos relacionados ao tratamento dos pacientes infectados pelo HIV. ${ }^{(13)}$

Sendo que a qualidade de vida dos portadores vem aumentando muito devido ao tratamento medicamentoso, apoio psicológico, social, entre outros. Segundo pesquisas recentes da Organização Mundial de Saúde, os soropositivos no processo de morbimortalidade, vêm adquirindo patologias como cardiopatias e diabetes, não correlacionadas diretamente ao HIV.

Levando-se em consideração o envelhecimento da epidemia e a sobreposição de patologias, fazem-se necessários consensos cada vez mais completos e abrangentes. O consenso desempenha uma função essencial, uma vez que não só norteia o tratamento em 
linhas gerais, mas também traz indicações em relação às profilaxias, interações medicamentosas, vacinas e manejo dos efeitos colaterais. ${ }^{(12)}$

Entretanto, o impacto do acesso universal ao tratamento ainda não é equânime no âmbito do SUS. Evidências recentes demonstram que pessoas menos escolarizadas e usuários de drogas injetáveis (UDI) têm uma tendência a menor sobrevida uma vez iniciada terapia. É essencial que os serviços que atendem PVHA desenvolvam programas e ações específicas direcionadas a estes segmentos populacionais. A assistência de excelência ao paciente com HIV/AIDS requer aplicação cotidiana de princípios de cuidado primário, medicina de família e abordagem de doenças crônicas. O conhecimento básico sobre múltiplas especialidades para o manejo adequado das complicações frequientemente associadas à infecção pelo HIV é fundamental, bem como, a atualização contínua sobre a terapia anti-retroviral. ${ }^{(12)}$

\section{TRATAMENTO}

A abordagem clínica da infecção pelo HIV e de suas complicações é bastante complexa. Com o advento da terapia anti-retroviral potente, as manifestações clínicas decorrentes da infecção pelo HIV tornaram-se menos freqüentes e houve melhora substancial do prognóstico e da qualidade de vida dos indivíduos que vivem com o HIV. Todavia, a resistência viral, a toxicidade das drogas e a necessidade de elevada adesão ao tratamento permanecem como importantes barreiras ao sucesso prolongado da terapia. Por conseguinte, a avaliação cuidadosa dos riscos e benefícios da terapia anti-retroviral no momento de sua indicação é crucial. ${ }^{(13)}$

O principal objetivo da terapia anti-retroviral é, através da inibição da replicação viral, retardar a progressão da imunodeficiência e restaurar, tanto quanto possível, a imunidade, aumentando o tempo e a qualidade de vida da pessoa que vive com HIV ou AIDS . A evolução natural da doença caracteriza-se por intensa e contínua replicação viral em diversos compartimentos celulares e anatômicos, que resulta, principalmente, na destruição e disfunção de linfócitos T que expressam o antígeno de membrana CD4 (linfócitos T-CD4+) e de outras células do sistema imune. A depleção progressiva dos linfócitos T-CD4+ leva à imunodeficiência, que em sua forma mais grave manifesta-se pelo surgimento de infecções oportunistas e neoplasias que caracterizam a Síndrome da Imunodeficiência Adquirida 
(AIDS). Assim, a supressão máxima e contínua da replicação viral é desejável para reduzir ou reverter o dano imunológico. ${ }^{(13)}$

A avaliação da resposta ao tratamento tem como parâmetros a redução da carga viral e o aumento (ou, pelo menos, a interrupção da queda) do número de linfócitos T-CD4+. Fazendo pra isso uso de medicamentos modernos e combinações com Inibidores de Transcriptase Reversa Análogo de Nucleosídeo ou Nucleotídeo, Inibidores de Transcriptase Reversa Não Análogo de Nucleosídeo ou Nucleotídeo e Inibidor da Protease. Todas essas medicações tem ações distintas, mas que podem ser combinadas, e assim evitando que o vírus utilize o material genético do hospedeiro e se reproduza.

Além do tratamento medicamentoso, o Ministério da Saúde também é responsável por gerar suporte emocional e de inclusão social, tudo em busca da vida saudável do portador do vírus, e quando necessário internação hospitalar para estabilizar ou sanar doenças oportunistas decorrentes da AIDS.

Faz parte do tratamento de adultos e adolescentes que vivem com HIV o esquema de vacinação, podem receber todas as vacinas do calendário nacional, desde que não apresentem deficiência imunológica importante. A medida que aumenta a imunodepressão, eleva-se também o risco relacionado a administração de vacinas de agentes vivos, bem como se reduz a possibilidade de resposta imunológica consistente. Sempre que possível, deve-se adiar a administração de vacinas em pacientes sintomáticos ou com imunodeficiência grave (contagem de linfócitos T-CD4+ inferior a 200 células/mm3, ate que um grau satisfatório de reconstituição imune seja obtido com o uso de terapia anti-retroviral, o que proporciona melhora na resposta vacinal e reduz o risco de complicações pós-vacinais. A administração de vacinas com vírus vivos atenuados em pacientes com imunodeficiência deve ser condicionada a analise individual de risco - beneficio e não deve ser realizada em casos de imunodepressão grave. $^{(8)}$

O programa nacional de combate à AIDS no Brasil, regulamentado pelo Governo Federal em 1996, garante aos doentes infectados com o vírus HIV acesso gratuito à medicação necessária para o tratamento. $\mathrm{O}$ coquetel de medicamentos anti-retrovirais usado no tratamento da doença é comprado pelo Ministério da Saúde e distribuído para a rede pública de saúde do país. ${ }^{(14)}$ 


\section{PREVENÇÃO}

O Programa Nacional de DST e AIDS passa pelo momento de consolidar diretrizes e estratégias para uma ação integrada com as diversas áreas programáticas do setor saúde. Com vistas na descentralização, tem havido iniciativas mais sistemáticas, por parte dos gestores federais, estaduais e municipais, de forma a articular o programa da AIDS com a atenção básica, no sentido da ampliação do diagnóstico e da atenção às DST/ AIDS no âmbito da rede básica de saúde, alem de passar informações e alertar a respeito de prevenção da doença. ${ }^{(7)}$

A prática do aconselhamento desempenha um papel importante no contexto da epidemia no Brasil desde a criação do Programa Nacional de DST/AIDS, e se reafirma como um campo de conhecimento estratégico para a qualidade do diagnóstico do HIV e da atenção à saúde. Quando avaliamos o que diferencia o campo da prevenção das DST/HIV/AIDS, da prevenção dos outros agravos, não podemos deixar de considerar a ação de aconselhamento. ${ }^{(7)}$

A incorporação do aconselhamento pelos serviços de saúde é um grande desafio, pois, até o momento, o aconselhamento realiza-se principalmente nos serviços de referência para as doenças sexualmente transmissíveis e AIDS e em algumas organizações não-governamentais. Esses serviços estão mais habituados a incluir na rotina de trabalho as questões sobre sexualidade, drogas e direitos humanos, parte indissociável dos campos da prevenção e do aconselhamento. $^{(7)}$

O Ministério da Saúde também utiliza os meios de comunicação e impressos para melhor repassar informações a respeito da prevenção e assim ajudar no controle da epidemia, além de distribuição gratuita de preservativos masculinos e femininos. Além de informações sobre compartilhamento de seringas e agulhas, no caso de usuários de drogas injetáveis.

No Brasil, as ações desenvolvidas para a prevenção das DST/ AIDS e a promoção da saúde primam pela recomendação do uso do preservativo em todas as relações sexuais. Abordagens que recomendam a diminuição do número de parceiros, a abstinência e a fidelidade não têm tido impacto entre as pessoas sexualmente ativas. ${ }^{(15)}$

Ampliar o acesso e a oferta do teste anti-HIV e do aconselhamento é uma importante estratégia para a prevenção do HIV. Mães soropositivas podem aumentar suas chances de terem filhos sem o HIV se forem orientadas corretamente a seguirem o tratamento durante o pré-natal. O diagnóstico precoce também possibilita uma assistência adequada ao portador do vírus, controlando o desenvolvimento da doença, a $\operatorname{AIDS}^{(7)}$ 
A institucionalização dessas ações permite a redução do impacto da epidemia na população, a promoção de saúde e a melhoria da qualidade do serviço prestado nas unidades de saúde. Permite também conhecer e aprofundar o perfil social e epidemiológico da comunidade de abrangência, dimensionar e mapear a população de maior vulnerabilidade e, com isso, reformular estratégias de prevenção e monitoramento. ${ }^{(7)}$

A Quimioprofilaxia Pós-Exposição também faz parte de uma medida preventiva sendo ela mais aplicada para acidentes ocupacionais com presença de materiais biológicos e também nos casos de violência sexual. A prescrição da quimioprofilaxia pós-exposição sexual ao HIV nos casos de violência não pode ser feita como rotina e aplicada a todas as situações. Ela exige uma avaliação cuidadosa quanto ao tipo e grau de risco da agressão, bem como o tempo decorrido até a chegada da pessoa agredida ao serviço de referência após o delito, sendo necessário um aconselhamento adequado nas diferentes situações, onde pode se indicar ou não a profilaxia com anti-retrovirais ,para que haja uma adesão adequada ao tratamento nos casos em que essa conduta for necessária. ${ }^{(16)}$

\section{REPRODUTIVIDADE}

Considerando-se que a forma sexual transmissão do HIV é responsável pela maior parte dos casos de infecção em homens e mulheres no Brasil, ${ }^{(17)}$ muitos estudos têm se centrado sobre o comportamento sexual dos indivíduos. De uma forma geral, os estudos indicam que a esfera da sexualidade foi afetada pela epidemia de HIV/AIDS, pois traz a idéia de risco às relações sexuais e afetivas os parceiros. Neste sentido, a ameaça de infecção pode abalar a segurança e a estabilidade dos relacionamentos, especialmente com relação à solicitação do uso de preservativos.

A presença desta infecção ao longo do processo reprodutivo apresenta riscos à saúde feminina e dos bebês, os quais devem estar claros, quando se considera a possibilidade da reprodução. Tendo em vista o grande avanço em tratamentos no Brasil, nos últimos anos, a reprodução de casais na presença do HIV pode ser considerada como mais segura que anteriormente, desde que respeitados alguns procedimentos, conforme será apresentado a seguir. Ainda assim, a maternidade/ paternidade na presença do HIV parece envolver importantes sobrecargas emocionais e conflitos psicossociais. ${ }^{(18)}$ 
O Ministério da Saúde por meio do Programa Nacional de DST e AIDS reuniu o Comitê Assessor para Recomendações de Profilaxia da Transmissão Vertical do HIV e Terapia Anti-Retroviral em Gestantes, que revisou as Recomendações de Terapia AntiRetroviral (TARV) e as demais condutas relacionadas à profilaxia da transmissão vertical do HIV. ${ }^{(12)}$ As recomendações que estão neste documento foram baseadas no conhecimento científico disponível e na experiência de especialistas na área, considerando sempre as condições de implementação das recomendações no Sistema Único de Saúde.

A taxa de transmissão vertical do HIV, sem qualquer intervenção, situa-se em torno de 25,5\%. No entanto, diversos estudos publicados na literatura médica demonstram a redução da transmissão vertical do HIV para níveis entre zero e $2 \%$, por meio de intervenções preventivas, tais como: o uso de anti-retrovirais combinados (promovendo a queda da carga viral materna para menos que 1.000 cópias/ml ao final da gestação), o parto por cirurgia cesariana eletiva, o uso de quimioprofilaxia com o AZT na parturiente e no recém-nascido, e a não amamentação. Nos países desenvolvidos, a ampla implementação dessas intervenções resultou na redução significativa da incidência de casos de AIDS em crianças. ${ }^{(12)}$

A implementação da atenção em planejamento familiar para assistir à concepção de casais que convivem com o HIV tem seus pilares pautados nos aspectos de traçar recomendações que reforcem o controle do risco de transmissão, recomendações que reduzam os riscos de transmissão vertical e proteger a saúde materna. Possui um equipe mínima, composta por ginecologista, urologista, enfermeira, psicóloga e assistente social, os Serviços de Assistência Especializada (SAE), serão a porta de entrada para os casais que convivem com o HIV, que desejam engravidar. ${ }^{(12)}$

Os Serviços de referência em reprodução humana assistida (RHA) para casais que convivem com o HIV entende-se por serviços que ofereçam atenção diagnóstica e terapêutica especializada, acompanhamento psicossocial, com condições técnicas, instalações físicas, equipamentos e recursos humanos adequados ao atendimento dos casais que vivem com o HIV. Para atender a essa finalidade esses serviços deverão estar articulados a uma central de regulação estadual e/ou municipal e do Distrito Federal que garanta a integração com o sistema local e regional, de procedimentos incluídos nas Tabelas SIH/SUS para RHA, tais como: ultrassonografia transvaginal, processamento seminal prognóstico, histeroscopia diagnóstica, histeroscopia cirúrgica, laparoscopia diagnóstica, microcirurgias, avaliação genética, pesquisa de cariótipo por banda, inseminação artificial, sendo facultativo, mas 
desejável a realização desses exames nesses serviços, além de atenção diagnóstica e terapêutica especializada, acompanhamento psicossocial, com condições técnicas, instalações físicas, equipamentos e recursos humanos adequados ao atendimento dos casais inférteis, enquadrado nos critérios de encaminhamento para os serviços de RHA. ${ }^{(12)}$

Esses serviços deverão estar articulados a uma central de regulação estadual, e/ou municipal e do Distrito Federal que garanta a integração com o sistema local e regional, que complementem as ações e realizem a fertilização assistida, conforme a Portaria SAS/MS n ${ }^{\circ}$ 388 de 06/07/05. . $^{(15)}$ Desta forma, garantindo assim o direito a reprodução dos soropositivos de maneira humanizada e sem riscos para ambos envolvidos no processo reprodutivo.

\section{NOVOS AVANÇOS}

\section{Gel de Tenofovir}

$\mathrm{Na} 18^{\circ}$ Conferência Internacional sobre AIDS, realizada em Viena em junho de 2009, a novidade de maior repercussão foi o gel vaginal microbicida à base de tenofovir (substância antiviral). As pesquisas apontaram a redução em 39\% as infecções do vírus HIV em mulheres, sendo aplicado 12 horas antes e 12 horas depois da relação sexual. Esta nova descoberta dos pesquisadores sul-africanos Salim e Quarraisha Abdool Karim, da Universidade de KwaZuluNatal, em Durban, foi publicada na revista científica Science. Sendo que a Organização Mundial de Saúde (OMS) e o Programa conjunto das Nações Unidas sobre o HIV/AIDS (Onusida) comemoraram este progresso nos avanços contra a AIDS, sendo que um dos benefícios do microbicida é que as mulheres podem utiliza-1 sem a necessidade da cooperação do seu parceiro sexual. Nesta pesquisa participaram 889 mulheres com idades entre 18 e 40 anos, que não eram portadoras do HIV e entre os efeitos secundários do gel houve a redução em $51 \%$ das infecções por herpes genital. O gel pode ser uma defesa especial para as mulheres cujos parceiros se recusam a usar preservativos. Novas formas de reduzir a propagação do HIV são extremamente necessárias, especialmente na África sub-saariana, onde quase $60 \%$ das pessoas infectadas com o vírus são mulheres. Elas muitas vezes são obrigadas a fazer parte de um sexo sem segurança, e são biologicamente mais vulneráveis à infecção pelo HIV do que homens. O gel foi considerado seguro quando utilizado uma vez 12 horas antes da relação sexual e 
uma vez nas 12 horas após a relação sexual, por mulheres com idade entre 18 e 40 anos. Após 30 meses, das 889 mulheres, 98 foram infectadas com o HIV - 38 no grupo que recebeu tenofovir em gel e 60 no grupo que recebeu placebo. As mulheres que usaram o gel corretamente eram muito menos prováveis de serem infectadas. Os investigadores dizem que as mulheres que usaram o gel também mostraram uma redução significativa no herpes genital, uma infecção sexualmente transmissível que por si só aumenta o risco de infecção pelo HIV. ${ }^{(19)}$

\section{Quimioprofilaxia Pré-exposição ( iPrex)}

Outro novo avanço é a Quimioprofilaxia Pré-exposição, que é o estudo intitulado por IPREX (também conhecido como Quimioprofilaxia para Prevenção do HIV em Homens ou Iniciativa PrEP), que nada mais é que uma iniciativa de profilaxia para pré-exposição do HIV. O iPrEx é um estudo randomizado, duplo-cego, controlado por placebo, orientado por eventos, para avaliar a segurança e a eficácia do uso de um medicamento tomado uma vez por dia, diariamente, por via oral, co-formulado de emtricitabina $200 \mathrm{mg} /$ tenofovir $300 \mathrm{mg}$ (FTC/TDF) para a prevenção da aquisição do HIV entre homens que são altamente expostos ao HIV e que também recebem um pacote completo de serviços de prevenção, que inclui exames anti-HIV e aconselhamento para redução de riscos, preservativos e controle de IST. ${ }^{(22)}$

Este estudo de pesquisa que tem o objetivo descobrir se o uso de um medicamento, tomado uma vez ao dia, pode complementar o sexo seguro para prevenir a infecção pelo HIV e pretende também mostrar se este medicamento é seguro, ou seja, não causa problemas de saúde para as pessoas que usam. A equipe brasileira passa a considerar travestis e mulheres transexuais como categorias não pertencentes ao gênero masculino. Com essa postura, os pesquisadores colocam-se ao lado da cidadania das travestis e transexuais, propondo à ciência um novo olhar sobre o segmento, desta vez mais humano e solidário. O estudo de pesquisa iPrEx está sendo realizado em Lima e Iquitos, no Peru; Guayaquil, no Equador; San Francisco e Boston, nos Estados Unidos; Chiang Mai, na Tailândia; Cidade do Cabo, na África do Sul. No Brasil, será realizado nos Estados de São Paulo e Rio de Janeiro. Em São Paulo, o estudo acontece no Prédio dos Ambulatórios do Hospital das Clínicas da Faculdade de Medicina da USP. ${ }^{(22)}$ 
O iPrEx, foi o primeiro estudo a relatar os dados de eficácia sobre o impacto da PrEP oral para a prevenção do HIV em pessoas. Os resultados iniciais do iPrEx foram divulgados em novembro de 2010, no New England Journal of Medicine. Constatando que o uso diário da associação de drogas antirretrovirais, emtricitabina $200 \mathrm{mg}$. e tenofovir $300 \mathrm{mg}$. (FTC/TDF), também conhecido como Truvada®, oferece $44 \%$ de proteção adicional contra a infecção pelo HIV em homosexuais e mulheres trans, quando fornecido com um conjunto abrangente de serviços de prevenção do $\mathrm{HIV}$, incluindo testes de HIV, aconselhamento de redução de risco, preservativos e exames e tratamento de infecções sexualmente transmissíveis (IST). A eficácia foi maior, em torno de $44 \%$, entre indivíduos que relataram na seleção que já tinham feito sexo anal receptivo do que entre aqueles que não fizeram. Os maiores índices de proteção foram encontrados entre as pessoas que usaram o comprimido de forma mais consistente. ${ }^{(23)}$

A profilaxia pré-exposição, ou PrEP, é o uso de medicações antirretrovirais, medicações geralmente usadas para tratar a infecção pelo HIV, para prevenir a infecção pelo HIV em pessoas não infectadas. O uso da PrEP para prevenir a infecção pelo HIV é um conceito experimental sendo atualmente avaliado em diferentes populações em risco para a infecção pelo HIV, incluindo usuários de drogas injetáveis, homens, travesti, mulheres trans e homens que fazem sexo com homens (HSH), e os heterossexuais. Atualmente, existem nove ensaios de PrEP ocorrendo em todo o mundo. O iPrEx tem uma extensa história de participação da comunidade. Com início em 2004, quando o iPrEx era apenas um conceito, os pesquisadores do estudo realizaram incontáveis consultas com líderes comunitários, defensores, pesquisadores, especialistas em ética, funcionários do governo e participantes do estudo potenciais e reais. Um programa de grupos de discussão, fóruns comunitários e entrevistas pessoais ajudou a melhorar continuamente os procedimentos de estudo. Todos os centros de estudo iPrEx mantém mecanismos que promovem a interação entre a comunidade e os pesquisadores do estudo, em um esforço contínuo para fazer do iPrEx um estudo de investigação verdadeiramente baseado na comunidade. ${ }^{(22)}$

O iPrEx OLE (OLE significa Open Label Extension, Extensão de Rótulo Aberto, em Português) é uma extensão do estudo iPrEx, com o objetivo de fornecer informações adicionais sobre segurança e comportamento durante o uso de longo prazo da PrEP. Espera-se também que os conhecimentos dos participantes de que a PrEP com Truvada fornece alguma proteção contra a infecção pelo HIV, e o fato de que todos os participantes HIV-negativos do 
iPrEx OLE sabem que eles estão recebendo Truvada e não um placebo, levará ao aumento do uso da droga do estudo pelos participantes e uma maior proteção contra a infecção pelo HIV. ${ }^{(22)}$

O iPrEx OLE teve a inclusão completa no final de 2011. Os participantes visitaram o centro de estudos nas semanas quatro, oito e doze, e depois a cada 12 semanas. O iPrEx demonstrou que Truvada é seguro e bem tolerado quando usado como PrEP. Amplos estudos demonstraram a segurança do Truvada em pessoas que vivem com o HIV, mas o iPrEx é o primeiro estudo a mostrar que a droga é segura e bem tolerada em pessoas que são HIVnegativas. ${ }^{(22)}$

A ingestão do comprimido é fundamental nas intervenções biomédicas de prevenção ao HIV auto-administradas, visto que a PrEP deve ser realizada constantemente para que funcione. No entanto, conforme demonstrado em um número de estudos, tomar um comprimido diariamente pode ser desafiador para algumas pessoas.

O uso de terapia antirretroviral para o tratamento da infecção pelo HIV é conhecido por diminuir a densidade mineral óssea, normalmente em 2 a $4 \%$ em média. No tratamento do HIV, a perda da densidade mineral óssea tipicamente ocorre nos primeiros 6 a 12 meses de tratamento e não progride a partir daí. O subestudo e distribuição de gordura do iPrEx foi concebido para identificar os efeitos do Truvada na densidade óssea ou na distribuiçao de gordura em pessoas saudáveis não infectadas pelo HIV. O iPrEx descobriu que a densidade mineral óssea tende a diminuir em até $1 \%$ entre participante que recebem Truvada no estudo. Esta foi uma diferença modesta, porém estatisticamente significante comparada ao grupo do placebo; entretanto, essa diminuição não foi associada a qualquer braço clínico; não houve mais fraturas no braço do Truvada que no braço do placebo. Estas análises incluíram dados coletados até a semana 24 de participação e nós estamos aguardando mais dados de acompanhamento e dados das visitas pós-interrupção. ${ }^{(22)}$

O estudo é patrocinado pela Divisão de AIDS (DAIDS) do National Institutes of Health (NIH, o Ministério da Saúde dos EUA) através de uma subvenção aos Institutos Gladstone em São Francisco, Califórnia. A droga é doada pelo laboratório Gilead Science, porém este não contribui financeiramente, nem participa no desenho do estudo, procedimentos ou análise dos dados do iPrEx. ${ }^{(22)}$

Truvada é um medicamento antirretroviral aprovado pelo FDA (órgão semelhante à ANVISA, nos EUA) para o tratamento de HIV/AIDS que combina dois medicamentos em um 
comprimido: o fumarato de tenofovir desoproxila (TDF, $300 \mathrm{mg}$ ) e a emtricitabina (FTC, 200 mg). É utilizado em combinação com outros medicamentos para o HIV (ARV) para tratar a infecção pelo HIV. Truvada bloqueia a transcriptase reversa, uma proteína do HIV que ajuda HIV a se replicar. O estudo iPrEx considerou que a utilização diária de Truvada fornece $44 \%$ de proteção adicional contra a infecção pelo HIV quando usado em combinação com um pacote de intervenções de prevenção do HIV: aconselhamento de redução de risco, fornecimento de preservativos, o tratamento de infecções sexualmente transmissíveis e testagem de HIV de rotina. ${ }^{(22)}$

Este resultado só foi demonstrado em homens e mulheres transexuais que fazem sexo com homens. Outros estudos em andamento estão verificado se Truvada pode reduzir o risco de infecção pelo HIV em pessoas heterossexuais e usuários de drogas injetáveis.

\section{Vacina}

Segundo a Organização Não-Governamental sem fins lucrativos International AIDS vaccine iniciativa o HIV infecta quase 7.400 pessoas por dia e uma vacina com $50 \%$ de eficácia distribuída para $30 \%$ da população mundial poderia proteger 5.6 milhões de indivíduos. Em conjunto com 40 laboratórios, o grupo trabalha na vacina desde $1996 .{ }^{(24)}$

O Brasil se tornou referência no combate à AIDS a partir de sua política de acesso, universal ao tratamento anti-retroviral, organizada por um programa eficiente, baseado na visão de política pública de seu Ministério da Saúde. Entretanto, os avanços no conhecimento da infecção pelo HIV que ocorrem no cenário internacional evidenciam a necessidade de esforços governamentais mais abrangentes para ampliar o desenvolvimento de novos processos e produtos que viabilizem a profilaxia da infecção pelo HIV no País. ${ }^{(24)}$

A versão do Plano Brasileiro de Vacina anti-HIV aqui apresentada tem, com esta perspectiva, o compromisso de implementar estratégias para o desenvolvimento de vacinas anti-HIV a partir da pesquisa básica e do aprimoramento de centros de pesquisa clínica, apoiadas por estudos sócio-comportamentais e por uma visão ética da pesquisa. Com esse objetivo, o Plano estabelece um Programa Integrado de Pesquisa, Desenvolvimento e Inovação em Vacinas anti-HIV, para o qual deverão convergir recursos nacionais e internacionais que garantirão as ações necessárias ao desenvolvimento e avaliação de novos produtos vacinais. ${ }^{(24)}$ 
Esse Programa, além de possibilitar o necessário apoio à atividade científica nessa área, viabilizará a consolidação de plataformas tecnológicas para vacinas recombinantes, por meio do fortalecimento das parcerias público-privadas, criando as necessárias condições para futura produção e distribuição no País. ${ }^{(25)}$

Uma vacina contra o HIV desenvolvida na Espanha obteve 90\% de sucesso em testes iniciais feitos com 30 voluntários de Madri e Barcelona. Apesar dos participantes não terem o HIV em seus organismos, a vacina deixou $90 \%$ deles preparados para um possível contato com o vírus que provoca a doença. Essa mesma resistência durou pelo menos um ano em 85\% dos voluntários. A idéia dos médicos do Hospital Clinic (Barcelona) e do Gregorio Marañon (Madri) foi "treinar" o corpo de pessoas sem a doença para que eles pudessem reconhecer o vírus HIV e células infectadas para atacá-los. Agora, o próximo passo será testar a vacina como terapia para pessoas que já possuem o vírus, mas ainda não desenvolveram a doença. Mesmo com o sucesso na primeira das três fases comuns dos testes em humanos, Felipe García, chefe da equipe que conduziu o estudo em Barcelona, afirma que é preciso cautela. Para o médico, o número de voluntário ainda é pequeno para poder dizer se a vacina vai mesmo garantir a defesa permanente do corpo contra o HIV. Para montar a vacina, os cientistas espanhóis colocaram quatro genes do HIV dentro do vírus enfraquecido da varíola. Segundo os pesquisadores, a presença desses genes não é suficiente para desenvolver a doença em pessoas sadias. Pelo contrário, ela serve somente para deixar o corpo em alerta para o caso do vírus de verdade entrar no organismo do vacinado, sendo testada em 2008 em roedores e em macacos. ${ }^{(25)}$

Outra vacina experimental ajudou a proteger macacos contra uma forma especialmente letal do vírus, aumentando as esperanças quanto à criação de uma vacina eficaz em humanos, disseram pesquisadores dos Estados Unidos. A vacina reduziu em 80\% o risco de contaminação entre os macacos expostos a uma versão símia do vírus, segundo o relato publicado na revista Nature. Entre os animais que foram contaminados, a carga viral no sangue era menor. Os cientistas ficaram especialmente animados porque o estudo contribuiu com a identificação de uma parte importante do sistema imunológico que é necessária para haver proteção contra o vírus HIV. O resultado é tão promissor que os pesquisadores já planejam testar a vacina em humanos no ano de 2013. Em 2009 um estudo com 16 mil pessoas na Tailândia mostrou pela primeira vez resultados animadores. No caso da vacina testada em macacos, foram usadas versões atenuadas de dois vírus comuns o adenovírus (que 
causa resfriados) e o vírus da varíola. Eles serviram de veículos para a administração do antígeno do vírus da imunodeficiência símia (SIV), provocando uma reação imunológica. Após vacinar os macacos, a equipe os expôs a uma versão agressiva do SIV. Após repetidas exposições, a maioria dos macacos acabou ficando contaminada, mas mesmo nessas circunstâncias a vacina ofereceu uma proteção adicional. Em seguida, a equipe realizou exames para descobrir qual parte do sistema imunológico dos macacos havia sido ativada. Eles descobriram que o "envelope" dos genes, usado pelos vírus para penetrar nas células, era crucial na proteção dos animais. O pesquisa com humanos só devem começar em janeiro de 2013. ${ }^{(10)}$

Pesquisadores da Universidade Federal de Pernambuco, em parceria com especialistas de outras universidades brasileiras, deram um passo importante na luta dos cientistas para formulação da vacina. Eles criaram um sistema para identificar os pacientes mais resistentes ao vírus HIV, o que pode levar ao desenvolvimento de uma vacina terapêutica para os pacientes infectados. Os pesquisadores já são conhecidos na comunidade científica internacional por outras descobertas. Eles já anunciaram a criação do HIV artificial para ajudar nas pesquisas. O trabalho é em parceria com a Universidade Federal do Rio de Janeiro e a Universidade de São Paulo. Desta vez, eles criaram um marcador genético a partir de uma proteína presente nas células de defesa, chamada NALP. A quantidade desta proteína está associada à maior ou menor resistência do sistema imunológico ao HIV. A descoberta do marcador genético a partir da proteína NALP nas células de defesa ou células dendríticas vai ajudar a definir os critérios de seleção dos pacientes que poderão tomar a vacina terapêutica. O grupo da Universidade Federal de Pernambuco já trabalha a dez anos na pesquisa de uma vacina terapêutica para os pacientes portadores do vírus HIV. A medicação não serve para prevenir a doença, mas para tratar os doentes. Na primeira fase, 18 pacientes tomaram a vacina. Metade deles teve a carga reduzida a quase zero. ${ }^{(6)}$

\section{CONCLUSÃO}

Desde o início da epidemia da AIDS o Brasil adota medidas que garantem o acesso gratuito e integral, além de investir na prevenção, tratamento, aconselhamento, e tantas outras medidas de políticas públicas de saúde que visam a melhoria da qualidade de vida dos 
portadores do HIV, bem como a garantia a reprodutividade e todos outros direitos a sua cidadania.

Deve-se destacar a importância de realizar maiores discussões e reflexões a fim de gerar mudanças, de forma a compreendermos melhor e mais profundamente tais aspectos, e assim melhorar os conhecimentos que serão posteriormente colocados em prática pelos futuros profissionais de saúde. Podendo-se gerar assim benefícios para os portadores do HIV e melhorias nesta área.

Este estudo demonstra alguns avanços que muito em breve trarão mudanças significativas, não só para os portadores do HIV, mas para toda a população mundial. Foi identificado que algumas informações sobre a temática não faziam parte do conhecimento geral dos profissionais da área de saúde, gerando assim uma deficiência nas informações referentes aos multifatores desta problemática de saúde pública.

É interessante ressaltar que embora os estudos relacionados ao HIV/AIDS contemplam grande importância e publicações, além de novos avanços tecnológicos, quando buscamos especificamente tais conhecimentos nos estudantes do campo da saúde o resultado é preocupante. Por isso, mesmo com todo o avanço a respeito da AIDS alguns graduandos e profissionais de saúde repetem condutas inadequadas que não correspondem aos conhecimentos atuais do HIV/AIDS, reproduzindo e aumentando a estigmatização que é repetida desde a década de $80,{ }^{(26)}$ quando nada se sabia a cerca do vírus. Infelizmente, ainda é uma realidade o relato de parcela expressiva dos pacientes soropositivos de que é mais fácil viver com o HIV do que com o preconceito.

\section{REFERÊNCIAS}

1. Brasil. Ministério da Saúde. Programa brasileiro de DST/AIDS. [acesso em 2010 maio 22]. Disponível em: http://www.aids.gov.br/main.asp?View $=\{$ CEBD192A-348E-4E7E-8735 B30000865D1C $\} \&$ Mode $=1$

2. Brasil. Ministério da saúde. Aprenda sobre HIV/AIDS. [acesso em 2010 maio 22]. Disponível em: http://www.aids.gov.br/data/Pages/LUMIS5F9787FCPTBRIE.htm

3. Brasil. Ministério da saúde. Monotoraids. [acesso em 2010 jun 14]. Disponível em: http://sistemas.aids.gov.br/monitoraids/\#

4. Brasil. Ministério da Saúde. Dados e pesquisas em DST e Aids. [online] 2010. [acesso 10 de novembro]. Disponível em: http:www.aids.gov 
5. Brasil. Ministério da Saúde. Programa nacional de DST e AIDS. Boletim epidemiológico AIDS. Brasília, DF, 2006; III(1).

6. Brasil. Ministério da saúde. Monotoraids. [acesso em 2012 abr 02]. Disponível em: http://sistemas.aids.gov.br/monitoraids/\#

7. Brasil. Ministério da saúde. Aconselhamento em DST/HIV/AIDS para a atenção básica. Brasília, DF; 2010.

8. Brasil. Ministério da saúde. Recomendações para terapia anti-retroviral em adultos e adolescentes infectados pelo HIV. Brasília; 2008.

9. Gil AC. Como elaborar projetos de pesquisa. 4a ed. São Paulo: Atlas; 2002.

10. UNAIDS. Hidden HIV epidemic amongst MSM in Eastern Europe and Central Asia. 2009; [acesso em 2012 jan]. Available at: http:// www.unaids.org/en/KnowledgeCentre/Resources/FeatureStories/archive/2009/20090126_MS MUkraine.asp

11. Vermelho LL, Barbosa HSR, Nogueira. AS Mulheres com AIDS: desvendando histórias de risco. Cad de Saúde Pública. 1999.

12. Brasil. Ministério da saúde. Secretaria de Vigilância em Saúde. Programa nacional de DST e Aids. Recomendações para terapia anti-retroviral em adultos e adolescentes infectados pelo HIV. 6ª ed. Brasília, DF; 2007.

13. Brasil. Ministério da saúde. Protocolo de assistência farmacêutica em DST/HIV/AIDS: recomendações do grupo de trabalho de assistência farmacêutica. Brasília; 2010. Normas e Manuais Técnicos.

14. Brasil. Ministério da saúde. Programa brasileiro de DST/AIDS. [acesso em 2012 fev 22].Disponível em: http://www.aids.gov.br/main.asp?View=\{CEBD192A-348E-4E7E-8735 B30000865D1C $\} \&$ Mode $=1$

15. Brasil. Ministério da saúde. Vivendo com HIV e AIDS. [acesso em 2010 jan 09].Disponível em: http://www.aids.gov.br/data/Pages/LUMIS29AE03E3PTBRIE.htm

16. Brasil. Ministério da saúde. Secretaria de Políticas de Saúde. Área técnica saúde da mulher. Prevenção e tratamento dos agravos resultantes da violência contra mulheres e adolescentes. Anexo I. Considerações gerais para profilaxia do HIV. 2a ed. Brasília; 2002.

17. UNAIDS. Report on the global AIDS epidemic. Geneva; 2008.

18. Carvalho FT; Piccinini CA. Maternidade em situação de infecção pelo HIV: um estudo sobre os sentimentos de gestantes. Interação em Psicologia, 2006.

19. REVISTA ABM. Salvador. Ed. Sete, n.7, Agosto de 2010. 52 p. 
20. Gomes P. Infecção pelo vírus da imunodeficiência humana tipo 2 (HIV-2). Proceddings $3^{\text {rd }}$ HIV-AIDS Virtual Congress; [2002?]. [acesso em 2012 jan]. Disponível em:

http://www.aidscongress.net/pdf/142.pdf

21. Tentrini M, Paim L. Pesquisa em enfermagem: uma modalidade convergente assistencial. Florianópolis: UFSC; 1999.

22. iPrEx OLE. [acesso em 2012 fev 28]. Disponível em: http://iprexole.com/indexpt.html

23. Robert M, Grant et al. Preexposure Chemoprophylaxis for HIV Prevention in Men Who Have Sex with Men. The New England Journal of Medicine. 2010.

24. Brasil. Ministério da Saúde. Secretaria de Vigilânica em Saúde. Secretaria de Ciência, Tecnologia e insumos estratégicos. Plano brasileiro de vacinas anti-HIV 2008-2012: pesquisa, desenvolvimento e inovação. Brasília; 2008.

25. Brasil. Ministério da Saúde. Secretaria de Vigilânica em Saúde. Secretaria de Ciência, Tecnologia e Insumos Estratégicos. Boletim Vacinas Anti-HIV/AIDS. Brasília; 2009. Grupo de Incentivo à Vida. n. 21.

26. Almeida TA. Fio da vida. Necessidades básicas dos pacientes infectados com o H.I.V. Salvador: Empresa Gráfica da Bahia; 1996. 